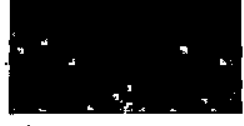

ARTIKEL

\title{
RINGKASAN'HASIL PENELITIAN
}

\author{
Sunardji Daromi
}

\section{Persepsi Wisatawan Mancanegara atas Atribut Produk Batik di Yogyakarta}

\section{Latar Belakang Penelitian}

Sebagai daerah tujuan wisata kedua sesudah Bali, dewasa ini Yogyakarta memiliki berbagai jenis industri dan pusat perdagangan cinderamata, mulai dari kerajinan batik, perak, kulit, bambu dan sebagainya. Dari hasil penelitian 1980 diketahui bahwa sektor ini mampu menyedot jumlah terbesar $(32 \%)$ pengeluaran wisatawan yang berkunjung di Yogyakarta (Proyek Pengembangan Pariwisata DIY, 1980). Khusus dari sektor ini ternyata batik memberikan sumbangan pendapatan daerah terbesar $(57,7 \%)$ dibanding jenis kérajinan lain. (Sumber : Kantor Statistik DIY dan Kantor Wilayah Departeman Perdagangan DIY).

Mengingat besarnya potensi yang dijanjikan oleh subsektor ini maka usaha pembinaan dan pengembangan industri dan perdagangan batik melalui penanganan aspek pemasaran akan merupakan suatu hal yang sangat penting. Usaha ini dapat dilakukan antara lain melalu penanganan pengembangan produk, disamping melalui aspek lain, seperti aspek harga, distribusi dan promosi. Usaha ini sudah barang tentu-memerlukan informasi pasar, yang salah satu diantaranya adalah informasi tentang persepsi konsumen atas atribut produk yang ditawarkan.

Melihat para wisman di Yogyakarta diperoleh gambaran bahwa wisman yang berkunjung memiliki latar belakang yang bermacam-macam. Mereka datang dari berbagai negara atau budaya (Eropa, Amerika, Australia, dan Asia); dengan berbagai motivasi kunjungan (alam, budaya, bulan mạdu, belanja); dengan usia dan jenis kelamin yang berbeda pula (Deparpostel, 1984). Atas dasar itu bukan mùstahil mereka memiliki persepsi dan keinginan yang berbeda pula ketika disajikan corak, desain, warna, harga serta atribut lain dari produk batik yang ditawarkan kepadanya.

Mendasarkan pada uraian diatas maka penelitian tentang persepși wisman atas atribut produk batik akan menjadi sangat bermanfaat sebagai masukan bagi usaha pembinaan dan 
pengambangan sektor ini, baik bagi instansi terkait, ataupun bagi perusahaan yang bersangkutan.

\section{Perumusan Masalah.}

Usaha pembinaan dan pengembangan industri dan perdagangan cinderamata batik melalui pengembangan atribut produk akan memerlukan informasi pasar, diantaranya adalan persepsi wisman atas atribut batik yang ditawarkan.

Karena persepsi wisman akan dipengaruhi oleh lingkungan kultural (asal negara), lingkungan sosial (keluarga) dan personal (jenis kelamin dan usia), maka penelitian ini akan mencoba untuk mengidentifikasi faktor kultural (asal negara), dan faktor personal (jenis kelamin dan usia) yang dapat digali, yang diduga mempengaruhi persepsi wisman atas atribut batik (corak/desain, warna, bahan, dan harga), serta mencoba mengkaji keterkaitan faktor-faktor tersebut dengan persepsi wisman atas atribut produk batik (warna, corak/ desain, bahan dan harga).

\section{Tujuan Penelitian}

3.1. Untuk mendapatkan gambaran umum tentang persepsi wisman (sebagai akibat adanya perbedaan negara asal, jenis kelamin dan usia) atas atribut produk batik di Yogyakarta, terutama menyangkut komponen komponen : corak/desain, warna, bahan dan harga.

3.2. Untuk mengetahui perbedaan persepsi wisman atas atribut batik yang terdiri atas warna, corak/ desain, bahan dan harga), sebagai

Gambar 01 : Model Perilaku Konsumen dari Kotler

\begin{tabular}{|ll|}
\hline \multicolumn{1}{|c|}{ OUTSIDE STIMULI } \\
\hline Marketing & Environmental \\
Product & Economic \\
Price & Technological \\
Place & Political \\
Promotion & Cultural \\
& \\
& \\
\hline
\end{tabular}

BUYER'S PURCHASE DECISIONS

\begin{tabular}{|c|c|}
\hline \multicolumn{2}{|c|}{ BUYER'S BLACK BOX } \\
\hline $\begin{array}{l}\text { Buyer's } \\
\text { characterisitics }\end{array}$ & $\begin{array}{l}\text { Buyer's Decision } \\
\text { Process }\end{array}$ \\
\hline $\begin{array}{l}\text { Cultural } \\
\text { Social } \\
\text { Personal } \\
\text { Psychological } \\
\qquad\end{array}$ & $\begin{array}{l}\text { Problem- } \\
\text { recognition } \\
\text { Information- } \\
\text { search } \\
\text { Evalution } \\
\text { Decision } \\
\text { Post Purchase- } \\
\text { behavior }\end{array}$ \\
\hline
\end{tabular}

Product choice Brand choice Dealer choice Purchase timing Purchase amount Purchase amount 
akibat adanya perbedaan negara asal, jenis kelamin dan usia para wisman.

\section{Kerangka Teoritik}

4.1. Ada tiga variabel yang perlu diperhatikan dalam mempelajari prilaku konsumen, yaitu variabel stimulus, variabel respons, dan variabel antara (intervening). Kotler (1986) menjelaskan hubungan stimulus respons dengan menggunakan bagan model prilaku beli konsumen sebagaimana gambar : 01 .

Model tersebut menggambarkan bahwa stimuli pemasaran dan lingkungan akan masuk ke kotak hitam pembeli dan menghasilkan respons pembeli. Stimuli pemasaran akan berupa kegiatan bauran pemasaran : produk, harga, promosi dan distribusi. Khusus untuk produk, stimuli ini dapat berupa jenis barang, merek, corak, desain, warna, bahan, dan sebagainya. Stimuli lingkungan dapat berupa kekuatan kekuatan ekonomi, teknologi, politik dan budaya. Semua stimuli diatas akan masuk ke kotak hitam pembeli dan menghasilkan keputusan beli konsumen sebagaimana digambarkan pada kotak paling kanan, yang berupa pilihan produk (corak, desain, warna, bahan) merek, dealer, waktu pembelian, dan jumlah pembelian.

4.2. Tentang komponen pertama dari kotak hitam, yaitu karakteristik pembeli, dijelaskan bahwa

Gambar 02 : Faktor-faktor yang Mempengaruhi Perilaku Konsumen dari Kotler

\begin{tabular}{|c|c|c|c|c|}
\hline Cultural & & & & \\
\hline \multirow[t]{4}{*}{ Culture } & Social & & & \\
\hline & \multirow{3}{*}{$\begin{array}{l}\text { Reference- } \\
\text { groups }\end{array}$} & Personal & & \\
\hline & & Age and life & Psychological & \\
\hline & & & Occupation & Motivation \\
\hline \multirow[t]{2}{*}{ Subculture } & \multirow[t]{2}{*}{ Family } & Economics & \multirow{2}{*}{$\begin{array}{l}\text { Perception } \\
\text { Learning } \\
\text { Beliefs and } \\
\text { attitudes }\end{array}$} & PEMBELI \\
\hline & & $\begin{array}{l}\text { Life style } \\
\text { Personality and }\end{array}$ & & \multirow[t]{3}{*}{ : } \\
\hline \multirow{2}{*}{$\begin{array}{c}\text { Social- } \\
\text { class }\end{array}$} & $\begin{array}{l}\text { Roles and } \\
\text { statuses }\end{array}$ & & & \\
\hline & & & & \\
\hline
\end{tabular}


komponen ini terdiri dari lingkungan budaya, lingkungan sosial, faktor personal dan psikologi. Elaborasi dari komponen ini dapat dilihat pada Gambar 02.

Model tersebut menggambarkan bahwa perilaku beli konsumen akan dipengaruhi oleh faktor psikologis dari individu yang bersangkutan. Faktor psikologis ini terdiri atas faktor motivasi, pengalaman belajar, persepsi, sikap dan kepercayaan. Faktor psikologis, yang didalamnya terdapat faktor persepsi, akan dipengaruhi oleh karakteristik individu konsumen, yang dibentuk oleh lingkungan kultural, sosial, dan personal. Lingkungan kultural akan terdiri dari kultur atau budaya, subkultur, dan kelas sosial dimana konsumen bersangkutan berada. Sebagai contoh, budaya tempat wisman berasal, misalnya Amerika, akan memberi pengaruh berbeda dengan Jepang. Faktor personal akan terdiri dari usia, daur hidup keluarga, jenis kelamin, pekerjaan, keadaan perekonomian keluarganya, gaya hidup, kepribadian dan konsep dirinya.

4.3. Khusus mengenai persepsi, Stanton (1987) menjelaskan sebagai "makna atau penilaian yang diberikan konsumen 'atas stimuli yang diterima melalui inderanya". Persepsi akan memberikan bentuk dan arah atas perilaku beli yang telah didorong oleh motif pembelian. Karena persepsi dipengaruhi oleh lingkungan kultural, keluarga, faktor personal serta psikologis lainnya, maka persepsi seseorang atas stimuli produk akan berbeda dengan lainnya karena perbedaan lingkungan yang mempengaruhinya.

Dengan melihat model tersebut maka dapatlah dikatakan bahwa perilaku konsumen akan terpengaruh oleh persepsinya terhadap produk yang ditawarkan. Persepsi akan dipengaruhi oleh faktor negara asal, jenis kelamin dan status keluarga. Sehingga bukan mustahil jika adanya perbedaan asal negara, jenis kelamin dan usia wisman akan sangat mempengaruhi persepsi mereka tentang atribut produk yang terdiri dari corak/desain, warna, bahan dan harga, yang pada akhirnya nanti akan mempengaruhi keputusan belinya. Seorang wisman mungkin menganggap bahwa desain merupakan faktor penting yang harus dipertimbangkan dalam membeli produk batik, sementara wisman yang lain mungkin lebih mementingkan atribut bahan dan sebagainya.

Berdasarkan kajian teori diatas maka tidaklah menyimpang jika faktor-faktor asal negara, jenis kelamin, dan usia merupakan faktor-faktor yang perlu dikaji sebagai faktor yang -mempengaruhi persepsi dan perilakubeli wisman dalam memilih cinderamata batik. Persepsi ini 
mungkin akan berupa pemberian makna sangat penting, penting dan tidak pentingnya atributatribut batik yang terdiri dari warna, corak atau desain, bahan, dan harga.

4.4. Atribut Produk sebagai Stimuli Pemasaran

Menurut Kotler (1988), untuk kepentingan pengembangan produk, maka produk dapat dirumuskan sebagai kumpulan atribut, berwujud ataupun tidak, yang didalamnya tercakup corak/desain, warna, harga, kemasan, prestise produsen serta pelayanan yang mungkin diterima pembeli sebagai sesuatu yang dapat memenuhi kebutuhannya. Untuk produk batik maka atribut tersebut dapat dinyatakan dalam warna, corak, desain, bahan, harga, merek dan . pelayanan penjual.

\section{Hipotesis yang Diajukan}

5.1. Ada keserasian penilaian terhadap atribut warna, corak/ desain, bahan dan harga batik diantara wisman Amerika, Australia, Eropa dan Jepang.

5.2. Tentang persepsi wisman, atas atribut-atribut : (a) warna (b) corak/desain (c) bahan dan (d) harga :

1) Tidak ada beda persepsi antara wișman yang berasal dari Amerika, Eropa, Australia maupun Jepang.

2) Tidak ada beda persepsi antara wisman pria dan wanita.
3).Tidak ada beda persepsi antara wisman berusia kurang dari 40 tahun dan berusia 40 tahun keatas.

4) Tidak ada interaksi diantara asal negara wisman dengan jenis kelamin; diantara asal negara wisman dengan kelompok usia; serta diantara asal negara, jenis kelamin dan kelompok usia.

\section{Metodologi Penelitian}

\subsection{Subyek Penelitian}

Subyek penelitian dalam penelitian ini adalah para wisman yang berkunjung di Yogyakarta. Responden yang dipilih adalah wisman yang telah melakukan pembelian cinderamata batik dan hampir mengakhiri kunjungannya di Yogyakara. Jumlah sampel ditentukan sebanyak 180 orang, menggunakan random sampling dengan teknik non probality sampling bertujuan. Klasifikasi tujuan dilakukan berdasar negara asal yaitu : (1) Eropa, (2) Amerika, (3) Australia, (4) Jepang.

6.2. Variabel yang akan diukur.

Variabel pengaruh (independent variables) akan terdiri dari :

1) Variabel negára asal yang dapat dibedakan dalam katagori Eropa, Amerika, Jepang dan Australia.

2) Vàriạbel jẹnis kelamin, yang dapat dibedakan dalam katagori pria dan wanita.

3) Variabel usia, yang dibedakan dalam kelompok berusia kurang 
dari 40 tahun (K-40) dan berusia 40 tahun keatas (40-K). : .

Variabel terpéngaruh berupa persepsi terhadap atribut produk batik yang dapat dibedakan menjadi atribut warna, corak/ desain, bahan dan harga.

6.3. Metode Pengumpulan data

Data sekunder diperoleh melalui sumber kepustakaan guna mendapatkan data yang berhubungan keadaan umum kepariwisataan dan, perdagangan - souvenir di DIY. Data primer diperoleh-melalui wawancara guna menggali "data-data mengenai negara asal, jenis kelamin, usia, pengalaman membeli batik, motivasi kunjungan, dan persepsi terhadap atribut produk batik. Wawancara dilakukan dengan menggunakan daftar pertanyaan panduan.

\subsection{Metode analisa data}

Untuk mendapatkan gambaran umum tentang faktor-faktor kultural dan personal yang diduga akan mempengaruhi persepsi wisman sebagaimana dikemukakan dalam tujuan nomor 1 akan digunakan metode diskriptif, dengan merujuk pada angka-angka prosentase atau indek skor. Sedang untuk menjelaskan keterkaitan antara variabel sebagaimana dirumuskan dalam hipotesis akan digunakan metode korelasi jenjang dari Kendall dan analisis varians klasifikasi ganda.
. Metode korelaśi Kendall di- - . maksudkan untuk mencari koefi-

1. - sien keserasian diantara kelompok' negara asal dalam menilai

- kemaknaan " atribut-atribut warna, corak/desain, bahan dan $\therefore$ harga. Sedang metode analisa varians klasifikasi ganda dimaksudkan untuk menjelaskan adanya atau tidaḱ ádanya perbedaan meán antăr kelómpok variábel. Variabel-variábel yáng ákan "diukur adalah" variabel-variabel : negara asal, jenis kelamin, usia sebagai variabel pengaruh dan variabel persepsi ataśs atribut warna, corak/desain, bahan dan harga sébagai variabel-variabel terpengàrựh.

\section{Hasil Penelitian}

7.1. Hasil analisis diskriptif.

7.1.1. Keadaan Umum Responden.

Berdasarkan pengelompokan data, dua pertiga responden $(66,1 \%)$ termasuk dàlam kategori usia kưrang dari 40 tahun, dan hanya sepertiga $(33,9 \%)$. yang berusia 40 tahun keatas. Dari pengelompokan jenis kelamin, total responden hampir terbagi sama, yaitu $48,4 \%$ pria dan $51,6 \%$ wanita. Hampir semua responden $(98 \%)$ menyatakan bahwa motivasi kunjungan mereka ke Yogyakarta adalah untuk tujuan wisata budaya dan wisata alam. Hanya sedikit (2\%) yang menyatakan tujuan wisata belanja dan wisata lainnya. 
Mengenai pengalaman membeli batik bukan Indonesia, hanya $39,4 \%$ dari total responden yang memiliki pengalaman sedang sisanya $(60,6 \%)$ menyatakan belum pernah memiliki pengalaman. Berdasarkan negara asalnya ternyata wisman Amerika merupakan kelompok terbanyak . memiliki pengalaman $(40,8 \%)$, kemudian baru disusul Jepang $(22,5 \%)$ dan Eropa $(25,4 \%)$, dan terkecil Australia (11,3\%).

Dari kelompok yang pernah memiliki pengalaman tentang batik bukan Indonesia, diperoleh penjelasan bahwa batik Malaysia merupakan jenis terbanyak dikenal (42 responden), baru kemudian batik Thailand (25 responden) dan terakhir Srilangka (6 responden). Tabel : 4.2. akan memberikan gambaran dari keadaan tersebut.

7.1.2. Persepsi Wisman atas Atribut Batik menurut Asal Negara.

Dari jawaban yang diberikan responden tentang persepsi atau pemberian makna terhadap atribut - warna, corak/desain, bahan dan harga - yang dinyatakan dengan memberi skor 1 sampai 4, menunjukkan bahwa semua responden memberikan pilihan tertinggi (skor 4 dan 3) hanya untuk atribut warna dan corak/desain. Tidak ada satupun yang memberikan skor 4 dan 3 untuk harga dan bahan. Atribut bahan dan harga hanya diberi skor antara 1 dan 2. Hasil peng- olahan data memberikan skor rata-rata tertinggi untuk atribut corak/desain (masing-masing 3,8 ), sedang responden Eropa dan Jepang lebih mementingkan pertimbangan warna (masingmasing 3,6). Lihat tabel 4.3 .

7.1.3. Persepsi Wisman atas Atribut Batik menurut Jenis Kelamin.

Berdasarkan perbedaan jenis kelamin, ternyata wisman wanita lebih mementingan warna (skor warna 3,53; skor corak/desain 3,46 ), sedang pria lebih mementingkan corak/desain (skor corak/desain 3,64; skor warna hanya 3,35). Secara terinci, wisman Amerika, baik pria maupun wanitanya mementingkan atribut corak/desain, Pria Australia lebih mementingkan atribut corak/desain sedang wanitanya memberikan makna seimbang untuk atribut warna dan corak/desain. Pria dan wanita dari Eropa dan Jepang lebih mementingkan atribut warna (lihat pada tabel : 4.4).

7.1.5. Persepsi Wisman terhadap Atribut Batik menurut Usia.

Dari tabel 4.5 diperoleh informasi bahwa baik kelompok wisman berusia kurang dari 40 tahun $(\mathrm{K}-40)$ ataupun 40 tahun keatas $(40-K)$ semuanya mempunyai persepsi yang sama. Mereka lebih mementingkan corak/desain diikuti warna baru kemudian harga dan bahan. 
Dikaitkan dengan asal negara, wisman Amerika dan Australia baik yang muda (K-40) maupun yang tua $(40-K)$ semuanya lebih mementingkan corak/desain baru kemudian warna. Wisman Eropa muda lebih mementingkan corak/desain, yang tua lebih mementingkan warna, sedang wisman Jepang tua maupun muda, keduanya lebih mementingkan warna. Keseluruhan wisman memiliki persepsi sama tentang harga dan bahan. Harga memiliki urutan ketiga dan bahan yang terakhir.

\subsection{Pengujian Hipotesis}

7.2.1. Pengujian Hipotesis tentang Keserasian Penilaian.

Uji hipotesis ini dimaksudkan untuk mengetahui apakah ada keserasian penilaian diantara wisman Amerika, Australia, Eropa dan Jepang terhadap atribut-atribut produk batik yang terdiri atas warna, corak/desain, bahan dan harga.

Dengan menggunakan taraf signifikansi $5 \% \mathrm{n}=4$ dengan data sampel $\mathrm{n}-1$ maka diperoleh harga X 2 tabel sebesar $=7.815$ (Tabel Values of $\mathrm{X} 2$ for specified Righ-Tail Areas). Sedang harga X 2 hitung diperoleh sebesar $=80,5$ Karena $\times 2$ hitung lebih besar dari X 2 tabel maka Ho ditolak, Ha diterima. Atau dengan kata lain ada keserasian penilaian kemaknaan atau persepsi diantara keempat kelompok wisman.
7.2.2. Pengujian Hipotesis tentang Persepsi Wisman Terhadap Atribut Warna.

Uji hipotesis ini dimaksudkan untuk mengetahui apakah ada perbedaan persepsi terhadap atribut warna diantara berbagai kelompok negara asal, jenis kelamin dan usia wisman.

Jika digunakan taraf signifikansi 5\% maka diperoleh hargaharga X 2 tabel (lihat tabel 4.8 : Ringkasan Analisis Varians pada kolom $\mathrm{Ft}$ ). Dengan membandingkan $F$ hitung dengan $F$ tabel, akan diketahui bahwa semua $F$ hitung lebih kecil dari $\mathrm{F}$ tabel, sehingga dengan demikian $\mathrm{Ho}: 1$ ) sampai dengan 4) diterima. Artinya bahwa tidak ada perbedaan signifikan antar kelompok negara asal, antar jenis kelamin dan antara kelompok usia. Juga bahwa tak ada interaksi antara asal negara dengan jenis kelamin, antar asal negara dengan kelompok usia, antara jenis kelamin dan kelompok usia, serta antara asal negara, jenis kelamin dan kelompok usia.

7.2.3. Pengujian Hipotesis tentang Persepsi Wisman Terhadap Atribut Corak/Desain, Bahan dan Warna.

Uji hipotesis ini dimaksudkan untuk mengetahui apakah ada perbedaan persepsi terhadap atribut-atribut (1) corak/desain, (2) bahan dan (3) warna diantara berbagi kelompok negara asal, jenis kelamin dan usia wisman. 
Dengan cara yang sama sebagaimana pada butir.4.2.2. baik untuk atribut (1) corak/desain, (2) bahan maupun (3) warna, telah diperoleh hasil yang sama pula, sehingga dapat disimpulkan bahwa tidak ada perbedaan signifikan antar kelompok negara asal, antar jenis kelamin dan antar kelompok usia. Juga 'tak ada interaksi antara asal negara dengan jenis kelamin, antara asal negara dengan kelompok usia, antara jenis kelamin dan kelompok usia, serta antara asal negara, jenis kelamin dan kelompok usia.

\subsection{Kesimpulan}

8:1.1. Ternyata hanya sepertiga dari seluruh responden yang memiliki pengalaman membeli batik non Indonesia. Diantara mereka paling banyak adalh wisman Amerika, diikuti Jepang, Eropa, dan terakhir Australia. Adapun jenis batik bukan Indonesia yang paling terkenal adalah batikMalaysia, diikuti Thailand dan terakhir Srilangka.

8.1.2. Tentang persepsi mereka atas atribut produk batik dapat disimpulkan bahwa secara total, corak/desain merupakan atribut yang dijadikan pertimbangan utama dalam memilih produk, kemudian diikuti warna, harga dan terakhir bahan. Analisis keserasian Kendall menguatkan bahwa memang ada sesuaian yang signifikan dalam penilaian atau pemberian makna atributatribut tersebut.
8.1.3. Khusus tentang ,persepsi mereka terhadap atribut corak/ desain dan warna, dari telaah tabel diperoleh rincian bahwa :

1) Wisman Amerika dan Australia baik pria maupuñ wanita, kelompok usia muda maupun tua semuanya menyatakan lebih mèmentingkan corak desain dari pada warna.

2). Wisman Eropa dan; Jepang, baik pria maupun wanita, kelompok usia muda maupun tua lebih mementingkan warna, kecuali bahwa wisman Eropa yang muda ternyata lebih mementingkan corak/desain.

8.1.4. Tentang persepsi mereka terhadap atribut bahan dan warna,itak ada perbedaan sedikitpun diantara mereka, baik berdasar asal negara, jenis kelamin maupun kelompok usia. Setelah corak/desain dan warna dijadikan pertimbangan pertama dan kedua dalam memilih produk batik, barulah menempatkan harga dan bahan pada urutan ketiga dan keempat.

8.1.5. Melalui metode analisis varians diperoleh kesimpulan bahwa persepsi atau penilaian wisman terhadap masing-masing atribut batik, ternyata tidak ada perbedaan signifikan baik diantara kelompok negara asal, jenis kelamin dan kelompok usia. Juga bahwa tak ada interaksi antara asal negara dengan jenis kelamin, antara asal negara 
dengan kelompok usia, antara jenis kelamin dan kelompok usia, serta antara asal negara, jenis kelamin dan kelompok usia.

8.1.6. Pendapat dan saran wisman terhadap batik Indonesia pada umumnya menyangkut masalah promosi, baru kemudian corak/desain dan warna :

1) Pada umumnya wisman memberikan penilaian yang sangat baik. Corak/desain, kualitas dan harga baik yang disajikan cukup bervariasi, sehingga memberikan cukup banyak kemungkinan pilihan.

2) Promosi dinilai terlalu sedikit. Disarankan agar promosi seperti brosur dan pasar seni diluar negeri lebih digalakkan.

3) Atribut warna dinilai kurang . tajam, kurang berani dan kadang kurang menarik.

4) Disarankan agar corak-corak tradisional ditambahkan.

5) Untuk jenis lukisan batik, justru dikehendaki agar dikembangkan' lukișan batik kontemporer.

\subsection{Rekomendasi}

8.2.1. Mengingat bahwa corak/ desain dan warna merupakan atribut yang dinilai sangat penting dalam memilih produk batik, maka pengembangan produk hendaknya lebih ditekankan pada dua atribut tersebut :
1). Pengembangan corak/desain dilakukan dengan menampilkan motif-motif tradisional.

2) Pengembangan warna diarahkan pada pemberian warna yang lebih tajam dan berani.

3).Pengembangan lukisan batik hendaknya ditujukan pada lukisan-lukisan kontemporer, dengan memperkaya variasi motif alam dan binatang.

8.2.2. Walaupun hasil pengujian Anava memberikan kesimpulan bahwa tak ada perbedaan persepsi diantara masing-masing kelompok wisman, namun perbedaan persepsi - atas atribut corak/desain dan warna - diantara wisman Amerika \& Australia dengan Eropa \& Jepang yang dihasilkan oleh analisis tabel, dapat kiranya dijadikan sebagai dasar segmentasi dalam pelayanan penjualan. Kepada wisman Amerika \& \& Australia dapat ditonjolkan corak/desain, sedang kepada wisman Eropa/ Jepang dapat ditonjolkan warna dalam menyajikan cinderamata batik.

\section{2:3. Mengingat banyaknya} kritik tentang promosi, maka kegiatan promosi perlu ditingkatkan, baik oleh fihak pengusaha, pedagang, maupun pemerintah, melalui berbagai media-media yang dinilai paling efektif. 